\title{
Management and treatment of distal ulcerative colitis
}

\author{
Andrea Calafiore, Chiara Praticò, Fernando Rizzello, Carlo Calabrese, Donatella Riso, Paolo Gionchetti, \\ Chiara Valerii, Massimo Campieri
}

Department of Clinical Medicine, IBD Unit, University of Bologna, S. Orsola-Malpighi Hospital, Bologna, Italy

\begin{abstract}
Ulcerative colitis (UC) is a chronic inflammatory condition that is confined to the colonic mucosa. Its main symptoms include diarrhea, rectal bleeding and abdominal pain. Approximately two-thirds of UC patients have disease confined distal to the splenic flexure, which can be treated effectively with topical therapy. This means the active drug can be delivered directly to the site of inflammation, limiting the systemic absorption and potential side effects. Topical treatment with aminosalicylates is the most effective approach in the treatment of these forms, provided that the formulation reaches the upper margin of the disease. Given this, the suppository formulation is the treatment of choice for proctitis and distal sigmoiditis. Thanks to their proximal spread, enemas, foams and gels represent the treatment of choice for proctosigmoiditis and for distal ulcerative colitis. Oral aminosalicylates are less effective than topical therapies in patients with active disease, while the combination of topical and oral treatment is more effective in patients refractory to topical or oral mono-therapy. Topically administered aminosalicylates play an important role in the maintenance of remission, but the long-term adhesion to therapy is poor. For this reason, the oral formulation is the first-line therapy in the maintenance of remission. Refractory patients can be treated with topical steroids or systemic steroids and TNF-alpha inhibitors in severe forms.
\end{abstract}

\section{Introduction}

The aim of treatment of ulcerative colitis (UC) is to induce and maintain both clinical and endoscopic remission. Once diagnosis has been confirmed, the main parameters to be evaluated in order to program therapy are the extension and the severity of lesions. In $90 \%$ of cases, patients with UC have a mild or moderate disease and over two-thirds of these patients have endoscopic evidence of disease confined distal to the splenic fixure.

Therefore, most of the patients with UC could be effectively treated only with topical therapy. Nevertheless, the therapeutic strategy must be decided with

Correspondence: Andrea Calafiore, Department of Clinical Medicine, IBD Unit, University of Bologna, S. OrsolaMalpighi Hospital, via Massarenti 9, 40138 Bologna, Italy. Tel. +39.051.6364122 - Fax: +39.051.6364129.

E-mail: calafiore.a@gmail.com

Key words: ulcerative colitis, 5-ASA, aminosalicylates, refractory, steroids, infliximab.

Conflict of interests: the authors declare no potential conflict of interests.

This work is licensed under a Creative Commons Attribution NonCommercial 3.0 License (CC BY-NC 3.0).

CCopyright A. Calafiore et al., 2013

Licensee PAGEPress, Italy

Italian Journal of Medicine 2013; 7:265-271

doi:10.4081/itjm.2013.265 the patient, taking into account his or her needs or preferences. Topical treatment has the advantage of guaranteeing delivery of a high dose of principle active ingredient directly to the site of inflammation, keeping systemic absorption of the drug to a minimum and, therefore, the frequency of adverse events.

\section{Treatment of mild-moderate active distal ulcerative colitis}

Topical preparations of 5-aminosalicylic acid (5ASA) is the treatment of choice for mild-moderate active distal UC. Different dosages and formulations have been tested in clinical studies over recent years, including suppositories, enemas, foams and gels. The various formulations differ not only in their chemical properties and dosage, but above all in their potential for proximal diffusion. ${ }^{1}$ Suppositories are the treatment of choice for proctitis and proctosigmoiditis limited to the distal colon. Scintigraphy studies have shown that the drug distributes itself mostly on the walls of the rectum and distal colon. ${ }^{2,3}$ In a multi-center randomized study of 242 patients with active proctitis, therapy with suppositories of $1 \mathrm{~g}$ of mesalamine was significantly more effective than hydrocortisone foam. ${ }^{4}$ Enemas, foams and gels, thanks to their retrodiffusion represent the treatment of choice for proctosigmoiditis involving the distal colon and for colitis involving the left side of the colon.

With liquid enemas, the most important characteristics for proximal diffusion are the volume administrated and the viscosity of the preparation. Enemas with 
bigger volumes have greater proximal diffusion, just as the foams and gels offer the advantage of prolonged retention and a more homogeneous covering of the inflamed mucosa. ${ }^{5-8}$ A randomized clinical trial comparing 5-ASA foam with 5-ASA liquid enemas showed that the foam was easier to retain and was better tolerated. ${ }^{9}$ More recently, 5-ASA gels were shown to be just as effective but was better tolerated than the formulations in enemas or foam and even easier to retain. ${ }^{10}$

Three recent meta-analyses reviewed all clinical studies from 1958 to 1997 . These clearly show that topical 5-ASA formulations are superior to placebos and to rectal corticosteroids in active distal UC. ${ }^{11-13}$ There is no evidence so far to support dose-related efficacy of topical 5-ASA therapy. Also oral aminosalicylates were shown to be effective in the treatment of active distal UC. ${ }^{14}$

Oral therapy, although preferred by the patient is less effective than topical therapy, ${ }^{13}$ above all in forms of active ulcerous proctitis, in which mesalamine suppositories achieve significantly better and quicker results than oral administration alone. ${ }^{15}$ The lower efficacy in these patients could be explained by the relative stasis in the uninvolved segment and by an accelerated transit in the inflamed tracts that means that the inflamed mucosa has less exposure to the orally administered drug. ${ }^{16}$ Nevertheless, combined therapy with oral and topical mesalamine is more effective than the single formulation if the oral-topical combination results in a larger quantity of the drug being administered. ${ }^{17,18}$ In fact, administration of mesalamine correlates with the mucosal concentrations achieved. ${ }^{19}$ When the oral formulation alone is compared with combined oral plus topical administration, but at the same dosage, the 2 treatments have similar efficacy. ${ }^{20}$ Guidelines from the European Crohn's and Colitis Organisation (ECCO) (statement 5B) propose topical therapy alone as first treatment choice in mild-moderate distal UC (EL1b, RG B) or combined with the oral formulation at a dose of $2 \mathrm{~g} / \mathrm{die}(\mathrm{EL} 1 \mathrm{a}, \mathrm{RG} \mathrm{A}) .^{21}$

Beclomethasone dipropionate (BDP) is a glucocorticoid steroid characterized by high receptor efficacy and by an intra-hepatic first pass effect that guarantees prompt elimination impeding the inhibitory action of the hypothalamic-corticoadrenal axis. $^{22}$ Treatment with topical BDP at a dose of 3 $\mathrm{mg} /$ die has similar efficacy to topical hydrocortisone in distal forms of UC but with a significantly reduced inhibition of the corticoadrenal action. ${ }^{23}$ More recently, topical BDP has been compared with topical mesalamine $1 \mathrm{~g}$ and showed similar efficacy, ${ }^{24} \mathrm{a}$ conclusion also confirmed by meta-analysis studies. ${ }^{25}$ When administration of only a topical drug is not capable of controlling the disease, the 2 drugs can be combined, as proposed by Mulder in 1996, demon- strating the greater efficacy of the BDP-mesalamine combination than that achieved with either drug on its own. ${ }^{26}$

In patients with active distal UC, with complete intolerance to topical therapy, one alternative is the mesalamine multimatrix (MMX) formulation. No difference in efficacy was observed in a comparison of oral MMX $3.2 \mathrm{~g} /$ die and topical mesalamine $4 \mathrm{~g} / \mathrm{die}$, but patients clearly prefered oral to topical treatment. ${ }^{27}$ Pharmacological treatment of mild-moderate active distal UC is summarized in Figure 1.

\section{Treatment of active distal ulcerous colitis refractory to traditional therapy}

Refractory colitis is a condition that most Authors define as no or partial response to traditional therapy. Management of these patients should include, above all, the exclusion of those factors that could limit or impede the efficacy of traditional therapy. Therefore, enteric infections should be excluded (Campylobacter jejuni, salmonella, shigella, cytomegalovirus, herpes simplex virus and parasitic infections) since each one of these is associated with disease relapse. Secondly, the diagnosis should be re-evaluated, excluding through endoscopic and histological re-examination a possible cholic site of Crohn's disease (CD).

Epidemiological studies have shown that proximal progression of the disease is observed in approximately half of the patients with proctitis or distal colitis, and this possibility must be taken into consideration in cases in which there is a worsening in the patient's clinical condition. ${ }^{28,29}$ Other factors that can cause a pseudo-refractory situation are: inadequate dosing, use of inappropriate formulations, treatment duration that is too short, intolerance to 5-ASA or reduced adherence to treatment. These should be excluded before making a diagnosis of refractory distal UC. More specifically, the correct dosage for ulcerous proctitis is represented by suppositories of $1 \mathrm{~g}$. Applied once a day these induce clinical and endoscopic remission quicker than $500 \mathrm{mg}$ suppositories applied twice a day and are also better tolerated by the patient. ${ }^{30,31}$

For forms of proctitis, the formulation in suppositories has been shown to be as effective as enemas, while guaranteeing greater tolerance and adherence to treatment by the patient. ${ }^{32}$ Also, a recent prospective study clearly demonstrated that $75 \%$ of patients with active distal colitis are not treated with topical formulations..$^{33}$ It should also be remembered that a suitable period of time is needed before a clinical response is seen; 6-8 weeks could be needed before clinical remission is obtained, according to the severity and the extension of the disease.

In rare cases, the use of 5-ASA formulations has led to a worsening of UC symptoms. In these cases, 
treatment must be interrupted and a possible intolerance or allergic reaction should be considered.

One of the biggest problems in the management of UC patients is that of compliance and adherence to treatment, both with oral 5-ASA therapy and, above all, with topical formulations. Often patients use as few enemas, suppositories or tablets as possible to control symptoms. In truly refractory cases, treatment of choice is combined therapy with topical BDP or topical steroids. If the patient remains refractory, treatment with systemic steroids is indicated (methylprednisolone $40 \mathrm{mg} /$ die or equivalent) or even TNF-alfa inhibitors are indicated. ${ }^{34}$

In Active Ulcerative Colitis Trials (ACT) with infliximab in moderate-severe UC, one-third of enrolled patients had distal disease involvement. On completion of eight weeks of treatment, approximately $35 \%$ of patients were in clinical remission while $65 \%$ had a reduction in symptoms and $60 \%$ had achieved mucosal cure. ${ }^{35}$ Guidelines of the ECCO (statement $5 \mathrm{H}$, LE 1b, GR B) and of the Italian Group for the study of Inflammatory Bowel Disease (IG-IBD) (statement 4A, LE 1b, GR A) confirm these indications. ${ }^{29,36}$
Figure 2 shows the management flow chart of distal UC refractory to traditional therapy.

\section{Maintenance therapy of distal ulcerative colitis}

A meta-analysis has demonstrated that topical administration of mesalamine is also the most effective maintenance treatment in distal UC. Enemas of mesalamine are superior to placebo in maintaining remission with efficacy rates of $52-92 \%$ and an odds ratio of 5.6. Rectal administration is also superior to sulfasalazine with an odds ratio of $2.3 .{ }^{37}$ A recent controlled study showed that treatment with slow release mesalamine $1 \mathrm{~g}$ suppositories administered 3 times a week is significantly better than placebo in preventing relapse and that in case of relapse, increasing the dose to $1 \mathrm{~g} /$ die is effective in inducing another remission. ${ }^{38}$ Patients who prefer not to continue topical treatment for a long period of time can also be effectively treated with oral mesalamine. ${ }^{39}$ Finally, maintenance treatment with a combination of oral and topical mesalamine was shown to be more effective in main-
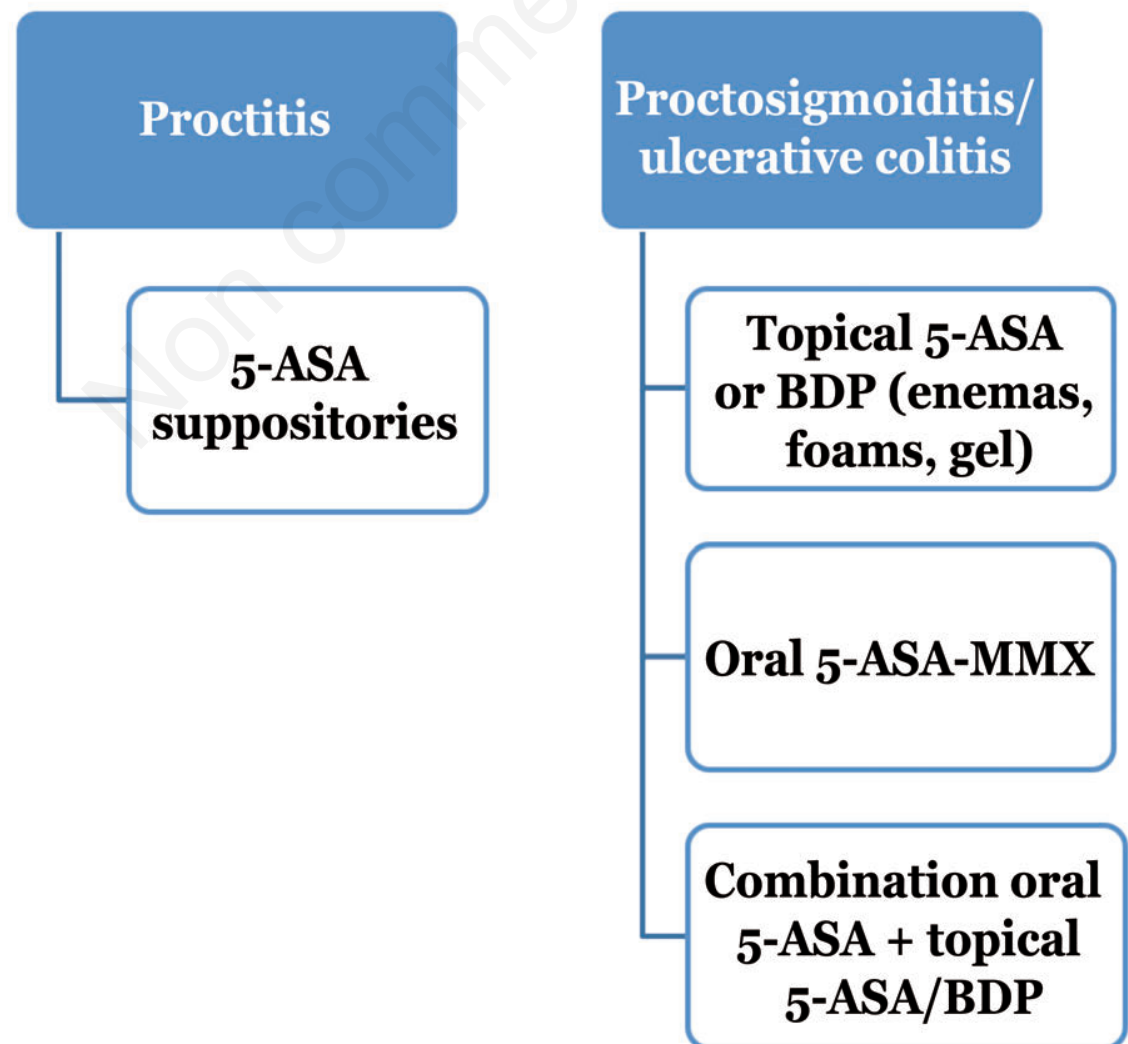

Figure 1. Traditional therapy for mild-moderate active distal ulcerative colitis. 


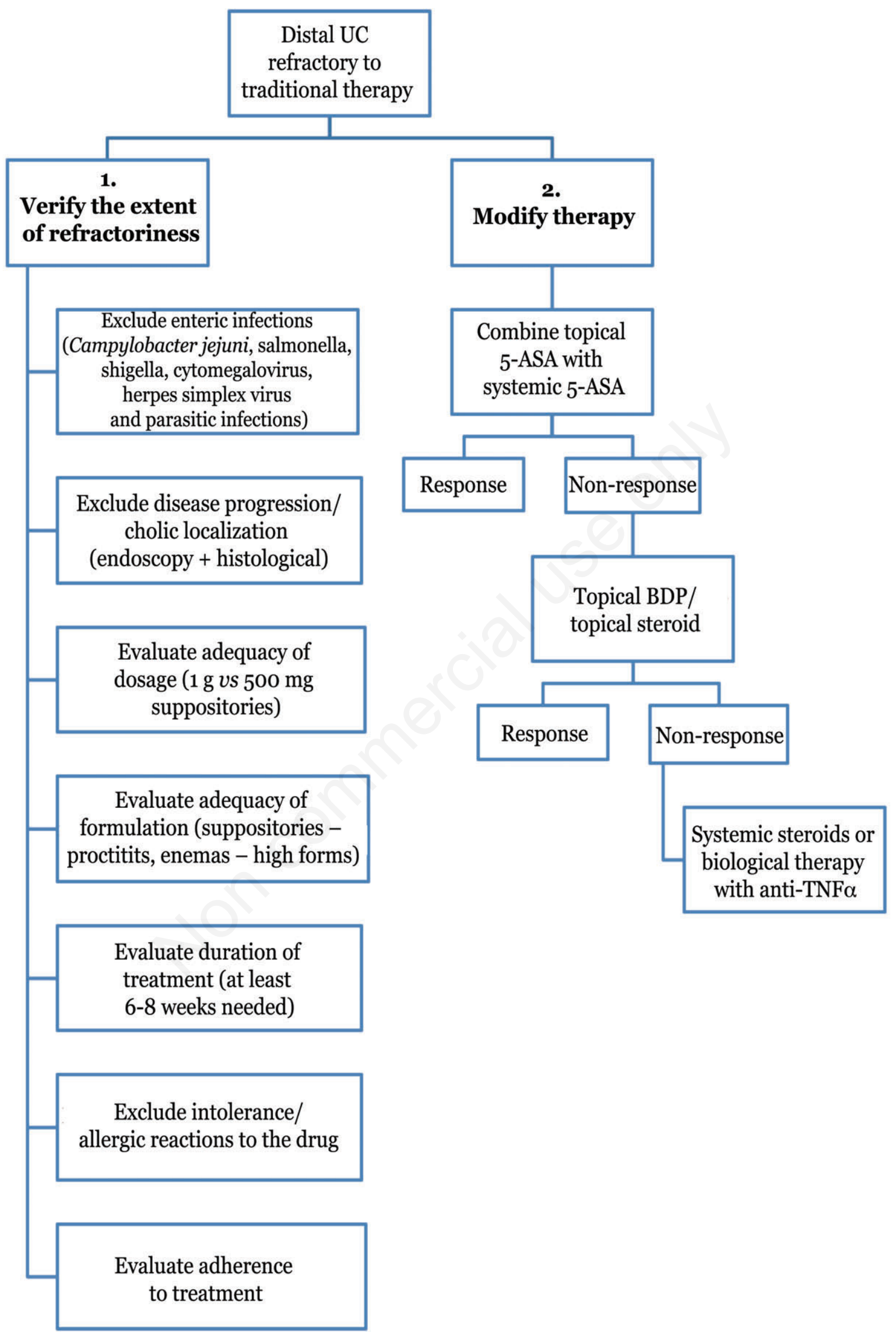

Figure 2. Management of mild-moderate active distal ulcerative colitis refractory to traditional therapy. 


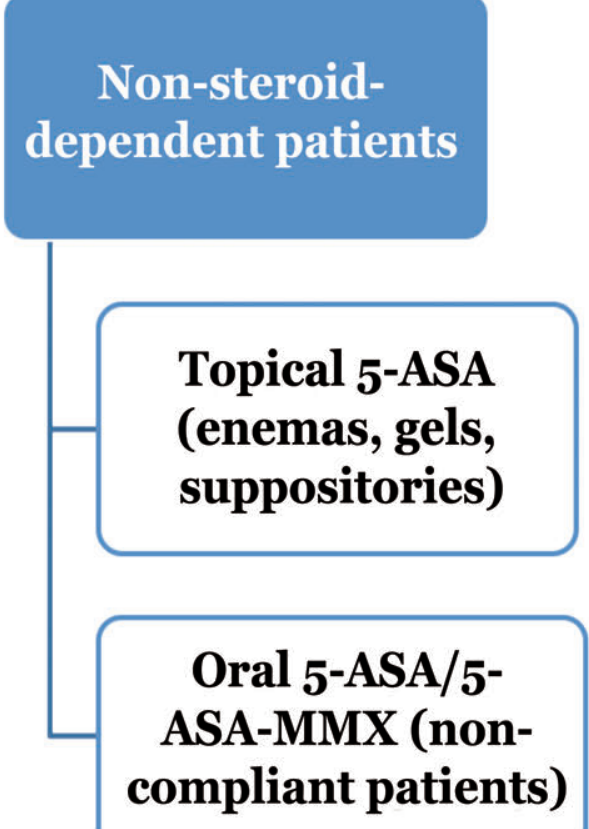

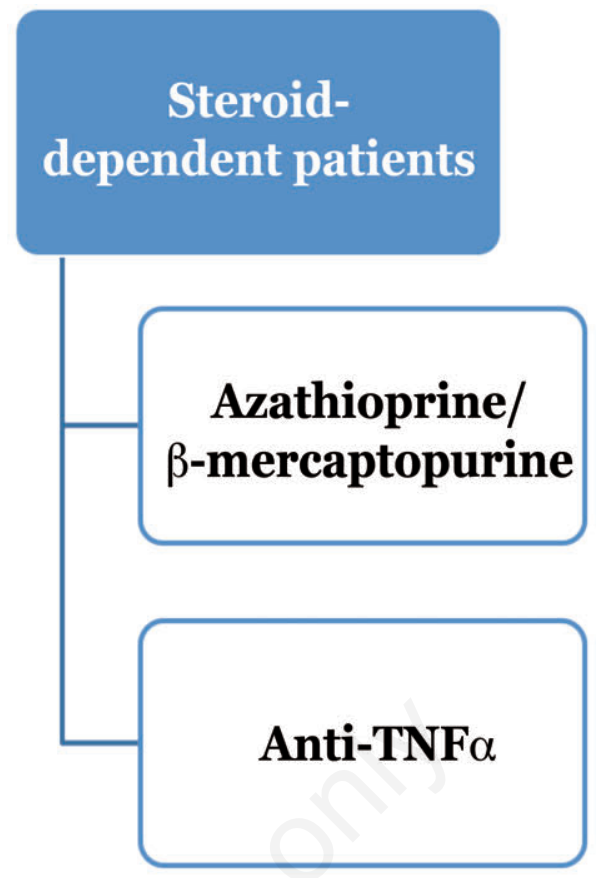

Figure 3. Maintenance therapy for distal ulcerative colitis.

taining remission and could be useful in patients at high risk of relapse. ${ }^{40-42}$

Oral mesalamine is also indicated in patients who have obtained clinical remission with systemic steroids but not in patients with corticodependence in whom the treatment of choice for maintaining remission is azathioprine. Also infliximab is effective in maintaining remission even though clinical studies were carried out for only one year. The experience of single centers for longer periods of time has shown good drug efficacy and safety.

Maintenance therapies for distal UC are summarized in Figure 3.

\section{Conclusions}

In conclusion, topical treatment with aminosalicylates is the treatment of choice for patients with active mild or moderate distal UC. The choice of formulation and dosage must be based on an evaluation of the extension and the severity of the inflammatory lesions. Also oral aminosalicylates are effective in active distal UC but to a lesser degree than topical formulations. Therapy with topical mesalamine is the most effective treatment for maintaining remission in distal UC, but those patients who prefer not to continue treatment with topical formulations for long periods of time can be effectively treated with oral mesalamine. The combination of oral and topical mesalamine is indicated for inducing remission in refractory patients and in maintaining remission in patients at high risk of relapse. The choice of therapy for maintaining remission depends on how the patient achieved control of the disease. Treatment with oral or topical mesalamine, in selected cases, is the treatment of choice when the acute phase was treated with mesalamine. Azathioprine can be used when the acute phase was treated with systemic steroids, or infliximab when remission was achieved with infliximab.

\section{References}

1. Gionchetti P, Rizzello F, Morselli C, et al. Review article: aminosalicylates for distal colitis. Aliment Pharmacol Ther 2006;24:41-4.

2. Williams CN, Haber G, Aquino JA. Double-blind placebo-controlled evaluation of 5-ASA suppositories in active proctitis and measurement of extent of spread using 99m-Tc labelled 5-ASA suppositories. Dig Dis Sci 1987;32:71S-5S.

3. Jay M, Beihn RM, Digenis GA, et al. Disposition of radiolabelled suppositories in humans. J Pharm Pharmacol 1985;37:266-8.

4. Lucidarme D, Marteau P, Foucault M, et al. Efficacy and tolerance of mesalazine suppositories vs hydrocor- 
tisone foam in proctitis. Aliment Pharmacol Ther 1997;11:335-40.

5. Wilding IR, Kenyon CJ, Chauhan S, et al. Colonic spreading of a nonchlorofluorocarbon mesalazine rectal foam enema in patients with quiescent ulcerative colitis. Aliment Pharmacol Ther 1995;9:161-6.

6. Van Bodegraven AA, Bower RO, Lourens J, et al. Distribution of mesalazine enemas in active and quiescent ulcerative colitis. Aliment Pharmacol Ther 1996;10:327-32.

7. Campieri M, Corbelli C, Gionchetti P, et al. Spread and distribution of 5-ASA colonic foam and 5-ASA enemas in patients with ulcerative colitis. Dig Dis Sci 1992; 37:1890-7.

8. Gionchetti P, Venturi A, Rizzello F, et al. Retrograde colonic spread of a new mesalazine rectal enema in patients with distal ulcerative colitis. Aliment Pharmacol Ther 1997;11:679-84.

9. Campieri M, Paoluzi P, D'Albasio G, et al. Better quality of therapy with 5-ASA colonic foam in active ulcerative colitis. A multicentre comparative trial. Dig Dis Sci 1993;38:1843-50.

10. Gionchetti P, Ardizzone S, Benvenuti ME, et al. A new mesalazine gel enema in the treatment of left-sided ulcerative colitis: a randomized controlled trial. Aliment Pharmacol Ther 1999;13:381-8.

11. Marshall JK, Irvine EJ. Rectal aminosalicylate therapy for distal ulcerative colitis: a meta-analysis. Aliment Pharmacol Ther 1995;9:293-300.

12. Marshall JK, Irvine EJ. Rectal corticosteroids versus alternative treatments in ulcerative colitis: a meta-analysis. Gut 1997;40:775-81.

13. Cohen RD, Douglas M, Woseth BA, et al. A meta-analysis and overview of the literature on treatment options for left-sided ulcerative colitis and ulcerative proctitis. Am J Gastroenterol 2000;95:1263-76.

14. Sutherland LR, May GR, Shaffer EA. Sulfasalazine revisited: a meta-analysis of 5-aminosalicylic acid in the treatment of ulcerative colitis. Ann Intern Med 1993; 118:540-9.

15. Gionchetti P, Rizzello F, Venturi A, et al. Comparison of oral with rectal mesalazine in the treatment of ulcerative proctitis. Dis Colon Rectum 1998;41:93-7.

16. Hebden JM, Blackshaw PE, Perkins AC, et al. Limited exposure of the healthy distal colon to orally-dosed formulation is further exaggerated in active leftsided ulcerative colitis. Aliment Pharmacol Ther 2000;14:155-61.

17. Safdi M, De Micco M, Sninsky C, et al. A double-blind comparison of oral versus rectal mesalamine versus combination therapy in the treatment of distal ulcerative colitis. Am J Gastroenterol 1997;92:1867-71.

18. Sandborn WJ, Hanauer S, Lichtenstein GR, et al. Early symptomatic response and mucosa healing with mesalazine rectal suspension therapy in active distal ulcerative colitis - additional results from two controlled studies. Aliment Pharmacol Ther 2011;34:747-56.

19. Frieri G, Pimpo MT, Palombo GC, et al. Rectal and colonic mesalazine concentration in ulcerative colitis: oral vs oral plus topical treatment. Aliment Pharmacol Ther 1999;13:1413-7.

20. Vecchi M, Meucci G, Gionchetti P, et al. Oral versus combination mesalazine therapy in active ulcerative colitis: a double-blind, double-dummy, randomized multicentre study. Aliment Pharmacol Ther 2001;15:251-6.
21. Travis SPL, Stange EF, Lémann M, et al. The European Crohn's and Colitis Organisation (ECCO) European evidence-based Consensus on the management of ulcerative colitis: Current management. J Crohn Colitis 2008;2:24-62.

22. Biancone L, Gionchetti P, Del Vecchio Blanco G, et al. Beclomethasone dipropionate versus mesalazine in distal ulcerative colitis: A multicenter, randomized, doubleblind study. Dig Liver Dis 2007;39:29-37.

23. Gionchetti P, D'Arienzo A, Rizzello F, et al. Topical treatment of distal active ulcerative colitis with beclomethasone dipropionate or mesalamine: a singleblind randomized controlled trial. J Clin Gastroenterol 2005;39:291-7.

24. Campieri M, Cottone M, Miglio F, et al. Beclomethasone dipropionate enemas versus prednisolone sodium phosphate enemas in the treatment of distal ulcerative colitis. Aliment Pharmacol Ther 1998;12:361-6.

25. Manguso F, Balzano A. Meta-analysis: the efficacy of rectal beclomethasone dipropionate vs. 5-aminosalicylic acid in mild to moderate distal ulcerative colitis. Aliment Pharmacol Ther 2007;26:21-9.

26. Mulder CJ, Fockens P, Meijer JW, et al. Beclomethasone dipropionate (3 $\mathrm{mg})$ versus 5-aminosalicylic acid (2 g) versus the combination of both $(3 \mathrm{mg} / 2 \mathrm{~g})$ as retention enemas in active ulcerative proctitis. Eur J Gastroenterol Hepatol 1996;8:549-53.

27. Prantera C, Viscido A, Biancone L, et al. A new oral delivery system for 5-ASA: preliminary clinical findings for Mmx. Inflamm Bowel Dis 2005;11:421-7.

28. Meucci G, Vecchi M, Astegiano M, et al. The natural history of ulcerative proctitis: a multicenter, retrospective study. Am J Gastroenterol 2000;95:469-73.

29. Langholz E, Munkholm P, Davidsen M, et al. Changes in extent of ulcerative colitis: a study on the course and prognostic factors. Scand J Gastroenterol 1996;31:260-6.

30. Gionchetti P, Rizzello F, Venturi A, et al. Comparison of mesalazine suppositories in proctitis and distal proctosigmoiditis. Aliment Pharmacol Ther 1997;11:1053-7.

31. Marteau P, Florent C. Comparative, open, randomised trial of the efficacy and tolerance of slow-release 5-ASA suppositories once daily versus conventional 5-ASA suppositories twice daily in the treatment of active cryptogenic proctitis: French Pentasa Study Group. Am J Gastroenterol 2000;95:166-70.

32. Campieri M, Gionchetti P, Belluzzi A, et al. 5-Aminosalicylic acid as enemas or suppositories in distal ulcerative colitis? J Clin Gastroenterol 1988;10:663-8.

33. Reddy SI, Friedman S, Telford JJ, et al. Are patients with inflammatory bowel disease receiving optimal care? Am J Gastroenterol 2005;100:1357-61.

34. Koutroubakis IE. Recent advances in the management of distal ulcerative colitis. World J Gastrointest Pharmacol Ther 2010;1:43-50.

35. Rutgeerts P, Sandborn WJ, Feagan BG, et al. Infliximab in induction and maintenance therapy for ulcerative colitis. N Engl J Med 2005;353:2462-76.

36. Orlando A, Armuzzi A, Papi C, et al. The Italian Society of Gastroenterology (SIGE) and the Italian Group for the study of Inflammatory Bowel Disease (IG-IBD) Clinical Practice Guidelines: The use of tumor necrosis factor-alpha antagonist therapy in inflammatory bowel disease. Dig Liver Dis 2011;43:1-20. 
37. Marshall JK, Irvine EJ. Putting rectal 5-aminosalicylic acid in its place: the role in distal ulcerative colitis. Am J Gastroenterol 2000;95:1628-36.

38. Marteau P, Crand J, Foucault M, Rambaud JC. Use of mesalazine slow release suppositories $1 \mathrm{~g}$ three times per week to maintain remission of ulcerative proctitis: a randomised double blind placebo controlled multicentre study. Gut 1998;42:195-9.

39. Sutherland L, Roth D, Beck P, et al. Oral 5-aminosalicylic acid for maintenance of remission in ulcerative colitis (Cochrane Review). Cochrane Database Syst Rev 2002;4:CD000544.
40. D’Albasio G, Pacini F, Camarri E, et al. Combined therapy with 5-aminosalicylic acid tablets and enemas for maintaining remission in ulcerative colitis: a randomized double-blind study. Am J Gastroenterol 1997;92:1143-7.

41. Frieri G, Pimpo MT, Galletti B, et al. Long-term oral plus topical mesalazine in frequently relapsing ulcerative colitis. Dig Liver Dis 2005;37:92-6.

42. Marshall JK, Thabane M, Steinhart AH, et al. Rectal 5aminosalicylic acid for maintenance of remission in ulcerative colitis. Cochrane Database Syst Rev 2012;11: CD004118. 